\title{
Location of the Mental Foramen Using Volumetrically Rendered CBCT Images
}

\author{
Wafa Mohammed Alfaleh
}

BDS, MSc

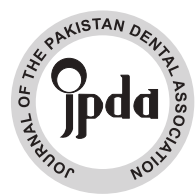

OBJECTIVE: To determine mental foramen location using volumetrically rendered Cone Beam Computed Tomography (CBCT).

METHODOLOGY: This is a retrospective study composed of data from 200 scans of patients which were referred to the oral and maxillofacial radiology clinic. Localization was done bilaterally based on the relationship between the mental foramen and posterior teeth in their long axes. six possible position were identified (Position 1: anterior to the first premolar, Position 2: in line with the first premolar, Position 3: between premolars, Position 4: in line with the second premolar, Position 5: between second premolar and first molar, Position 6: in line with first molar). For analysis descriptive statistic were used (mean and frequency).

RESULTS: In total, 200 scans were analyzed, $112(56 \%)$ were females and $88(44 \%)$ males with a mean age of 32.5 years $( \pm 13.1)$. Four hundred sites were assessed. The most common position of the mental foramen was in line with the second premolar (position 4) with a prevalence of $45.5 \%$, followed by position $3(41.5 \%)$. The prevalence of the other mental foramen position types combined (type 1,2,5 and 6) were 13\% .bilateral symmetry was noted in $71 \%$ of the cases.

CONCLUSIONS: Mental foramen location can be variable therefore, clinicians should be aware about this variation before surgical procedures involving mental foramen region. CBCT is recommended to avoid possible complication.

KEY WORDS: Mental Foramen, panoramic radiography, Mandible, CBCT.

HOW TO CITE: Alfaleh WM. Location of the mental foramen using volumetrically rendered CBCT images. J Pak Dent Assoc 2020;29(1):19-23.

DOI: https://doi.org/10.25301/JPDA.291.19

Received: 24 April 2019, Accepted: 02 October 2019

\section{INTRODUCTION}

$\mathrm{O}$ ne of the major advances in the past decade in dentistry was the introduction of Cone Beam Computed Tomography (CBCT). It reconstructs a virtually $3 \mathrm{D}$ image using a cone-shaped beam in a single scan. ${ }^{1-4}$ The Mental Foramen (MF) is an important anatomical structure located on the buccal surface of the mandible, frequently in a position superior to the mandibular canal. The canal forms a curve during its course anterior to the MF, it provides sensory innervations and nutrition to the gingiva, soft tissue of the chin and lower lip..$^{6,7}$

Accurate localization of the MF is hard due to the lack of consistent anatomical landmarks for reference and is clinically not accessible for visualization or palpation. ${ }^{8}$ Variable anatomical positions of the foramen have been described in the literature. ${ }^{8-10}$ Accurate localization of MF prior to any surgical procedure is essential in order to avoid damage to the mental nerve, and hence rendering the patient with a numb lower lip. Direct observation and measurements

1. Associate Professor, Department of Oral Medicine and Diagnostic Science, King Saud University, College of Dentistry.

Corresponding author: "Dr. Wafa Mohammed Alfaleh" < walfaleh1@ksu.edu.sa > on dry mandible has demonstrated the vertical position of the foramen to be frequently inferior to the apices of the mandibular second premolars. It lies midway between the crest of the alveolar ridge and the inferior border of the mandible. ${ }^{11}$ Most of previous studies on the location of the MF have used panoramic radiographs. However, panoramic radiography has some limitations in accurate identification and localization of MF due to its inherent magnification and geometrical distortion.

In 2013, Von Arx et al ${ }^{12}$ evaluated the MF position using corrected CBCT images and found that it was located between the two premolars in $56 \%$ of cases, whereas Khojastepour et al ${ }^{13}$ in 2015 studied MF location in Iranian population using CBCT images and found that the most common location was below the second premolar. Volumetric rendering (VR) is now a common image processing tool available in most CBCT image processing software utilized by clinician in the dental field. The objective of this study is to determine the location of the MF in a group of patients and assess the symmetry on both sides using CBCT with a volume rendering imaging processing tool. The results will be compared with findings in previous studies. 


\section{METHODOLOGY}

This study was approved by institutional review board of College of Dentistry, King Saud University, Riyadh, Saudi Arabia. Registration number NF2277.

The study was conducted retrospectively from CBCT scans of 200 patients seen in the Oral and Maxillofacial Radiology clinic at the College of Dentistry at King Saud University, Riyadh, Saudi Arabia. The CBCT examinations were originally done for various reasons, more commonly, implant site assessment, TMJ, orthognathic surgery preoperative assessment. None of the scans were done for the evaluation of position of MF.

\section{Exclusion criteria:}

- Completely edentulous mandible.

- Patients with missing teeth between mandibular first premolar to mandibular first molar on either side.

- Double mental foramen

- Patients with pathological lesions in the mandible that may affect the location of the MF

- History of trauma or surgical intervention in the premolar area.

Patients had been scanned with Iluma (Imtek Imaging, $3 \mathrm{M}$ Co., USA) with a large field of view .The CBCT examination were performed for each patient utilizing 3.8 $\mathrm{mA}, 120 \mathrm{kV}$, and a 40 second exposure time with $0.29 \mathrm{~mm}$ reconstruction voxel size. The volumetric data set for each patient were saved on the workstation linked with the CBCT. After acquisition of the volume, the DICOM data was transferred in order to generate a 3D volumetrically rendered image of the patients using Iluma vision 3D softwear. Based on the classification proposed by Al Jasser and Nwoku (1998)14 the location of the MF in relation to the teeth was identified according to the following.

Position 1: Situated anterior to the first premolar Position 2: In line with first premolar

Position 3: Between the first and second premolars Position 4: In line with second premolar

Position 5: Between second premolar and first molar Position 6: In line with first molar

The 3D volumetrically rendered image was examined by oral and maxillofacial radiologists (author). All images were evaluated in standard dim light condition. The right and left mental foramina were observed separately and recorded on a specially designed form.

Descriptive statistics of various positions were used (mean and frequency). The results were presented according to side and gender. The SPSS (version 21) was used for analysis. The mean and standard deviation of all the measurements were assessed. Comparison of value of all measurements was made between sides and genders using Chi square -test. Differences between genders were considered significant at $\mathrm{P}<0.05$.

\section{RESULTS}

Two hundred CBCT images were analyzed .The mean age of the participants in the current study was $32.5 \pm 13.1$ years. $112(56 \%)$ were females and $88(44 \%)$ were males. The most common position for the MF in this sample was position 4 (45.5\%), followed by position 3 (41.50\%). Position 5 was found to be $11.25 \%$, whereas. Positions 1, 2, or 6 were infrequently reported as shown in Figure1. Figure 2 shows the percentage of MF position of both genders, position 4 was the most common among females $(49.11 \%)$ whereas Position 3 was the most common among males (45.45\%). Figure $3 \& 4$ demonstrate the $3 \mathrm{D}$ volume rendering of position $4 \& 3$ respectively. Table 1, demonstrate frequency

Fig 1: The Percentage of the Most Common Mental Foramen Positions
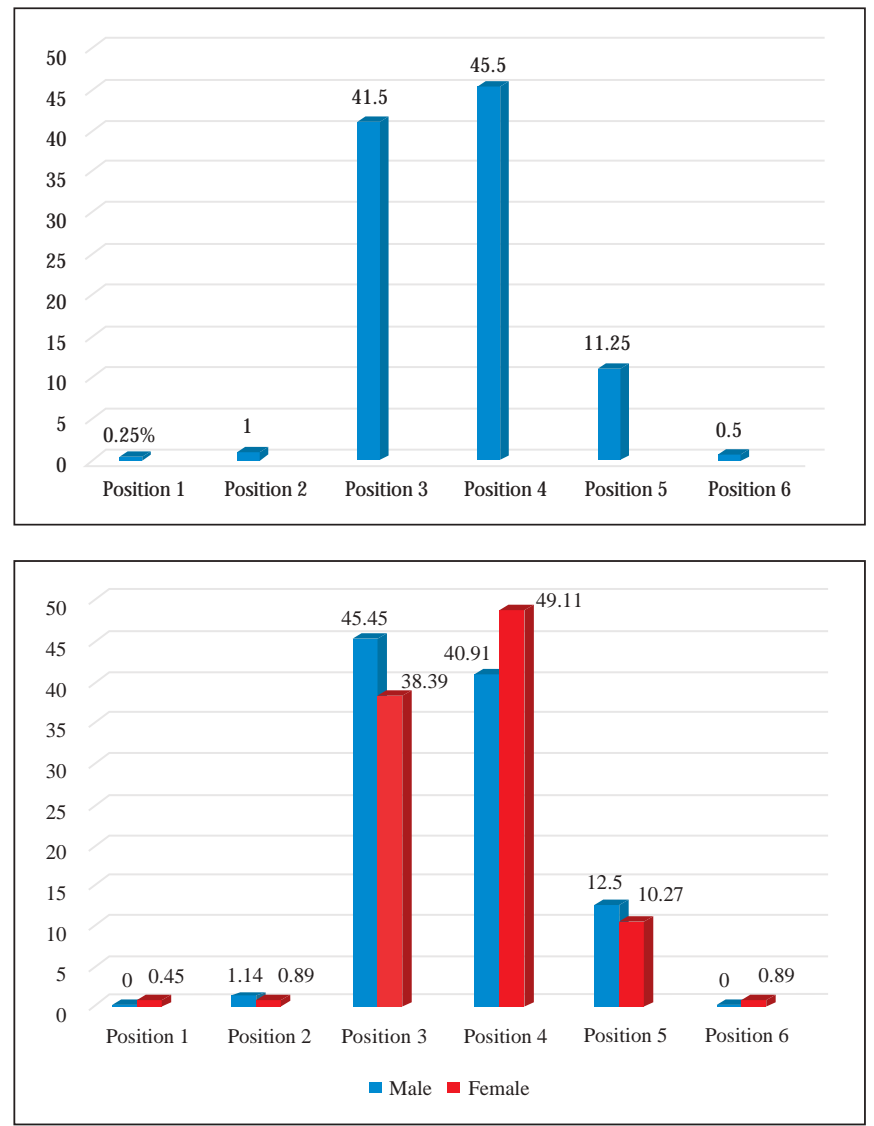

Fig 2: The Percentage of Various Positions of Mental Foramen among Males and Females 


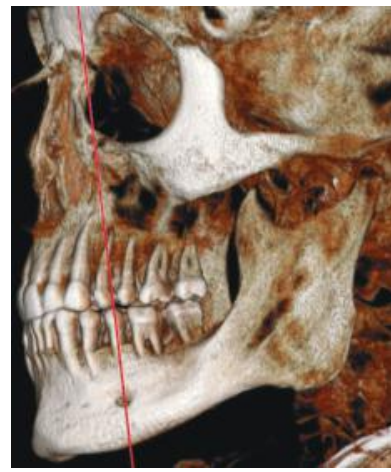

Fig 3: 3D volume rendering CBCT image demonstrating the position of MF. In line with the long axis of the second premolar (position 4).

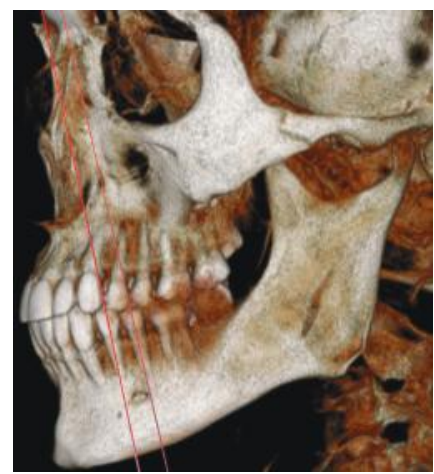

Fig 4: 3D volume rendering CBCT image demonstrating the position of MF between the first and second premolar (position 3).
Table 1: Frequency and percentage of MF position based on gender for right and left side.

\begin{tabular}{|c|c|c|c|c|c|}
\hline \multirow{2}{*}{ Position } & \multicolumn{3}{|c|}{ Male } & \multicolumn{2}{c|}{ Female } \\
\cline { 2 - 5 } & $\begin{array}{c}\text { Right frequency } \\
(\%)\end{array}$ & $\begin{array}{c}\text { Left frequency } \\
(\%)\end{array}$ & $\begin{array}{c}\text { Right frequency } \\
(\%)\end{array}$ & $\begin{array}{c}\text { Left frequency } \\
(\%)\end{array}$ & \\
\hline 1 & $0(0)$ & $0(0)$ & $1(0.89)$ & $0(0)$ & $1(0.25)$ \\
\hline 2 & $2(2.27)$ & $0(0)$ & $0(0)$ & $2(1.79)$ & $4(1)$ \\
\hline 3 & $38(43.18)$ & $42(47.73)$ & $42(37.50)$ & $44(39.29)$ & $166(41.50)$ \\
\hline 4 & $35(39.77)$ & $37(42.05)$ & $58(51.79$ & $52(46.43)$ & $182(45.50)$ \\
\hline 5 & $13(14.77)$ & $9(10.23)$ & $10(8.93)$ & $13(11.61)$ & $45(11.25)$ \\
\hline 6 & $0(0)$ & $0(0)$ & $1(0.89)$ & $1(0.89)$ & $2(0.5)$ \\
\hline
\end{tabular}

Table 2: Position of mental foramen by gender and symmetry

\begin{tabular}{|c|c|c|c|}
\hline \multirow{2}{*}{1} & & Symmetry & Asymmetry \\
\cline { 2 - 4 } & Gender & Frequency (\%) & Frequency (\%) \\
\cline { 2 - 4 } & Male & $0(0)$ & $0(0)$ \\
\cline { 2 - 4 } & Female & $0(0)$ & $1(100)$ \\
\hline \multirow{2}{*}{3} & Male & $0(0)$ & $2(100)$ \\
\cline { 2 - 4 } & Female & $0(0)$ & $2(100)$ \\
\hline \multirow{2}{*}{4} & Male & $68(85)$ & $12(15)$ \\
\cline { 2 - 4 } & Female & $64(74.42)$ & $22(25.58)$ \\
\cline { 2 - 4 } & Male & $50(69.44)$ & $22(30.56)$ \\
\hline \multirow{2}{*}{5} & Male & $10(45.45)$ & $12(54.55)$ \\
\cline { 2 - 4 } & Female & $10(43.48)$ & $13(56.52)$ \\
\hline 6 & Male & $0(0)$ & $0(0)$ \\
\cline { 2 - 4 } & Female & $2(100)$ & $0(0)$ \\
\hline \multirow{2}{*}{6} & & & $30(27.27)$ \\
\hline
\end{tabular}

and percentage of MF position based on gender for right and left side.

There was no statistically significate difference between right and left side of both gender using Chi square test with $\mathrm{P}>0.05$

For the entire sample, $71 \%(n=142)$, MF was symmetrically located where as in $29 \%(n=58)$ of the subject the MF was not symmetrically located. In terms of gender difference, MF was found to be symmetrical in $70 \%$ of females and $73 \%$ of males. The difference was not found to be statistically significant with $\mathrm{P}>0.05$.

The most common position that located symmetrically was position 3 (46.48\%) followed by position 4 (45.77\%). Whereas cases observed in position 1 or 2 were not symmetrically located. (Table 2 ).

\section{DISCUSSION}

Variation in the MF location has been reported in literature worldwide. Precise identification of MF location is critical both in diagnostic and clinical procedures. The most common locations of the MF as described within the literature have been below the apex of the first premolar or consistent with the second premolar or between them. Racial and gender differences have been reported in the literature. ${ }^{11,13,15}$

Previous studies on the MF location in White North American, British and Turkish populations found that the MF was located in line with the first premolar. In Asians, the MF was located in line with the second premolar where as in Africans, the location was posterior to second premolar. ${ }^{16-20}$

The position of mental foramen on panoramic radiographs is affected by the horizontal course of inferior alveolar nerve. ${ }^{21}$ Studies have reported that in up to $25 \%$ of cases, important structures such as the MF cannot be precisely determined when using panoramic radiographs. ${ }^{8}$

When compared to CBCT.. Various reasons have been cited, including improper patient positioning, acute bending during rotation of the tube and film around the patient's head. ${ }^{22,23}$ However, in this study, MF was clearly recognized in all samples as images were acquired using VR CBCT. Al-Mahalawy et al. (2017) ${ }^{15}$ used panoramic and CBCT images, whereas Naik et al. $(2017)^{11}$ used dry mandible and Ngeow and Yuzawati used panoramic radiography $(2003)^{24}$ for evaluation of MF position and found that the most common position was in line with the second premolar (position 4) followed by position 3 which is the same finding reported in this study; however, this study examined the location of the MF using only VR CBCT images. In 2013, Von Arx et al ${ }^{12}$ conducted a study to evaluate MF position using corrected. 
CBCT images and found that the most common location was between the two premolars (position 3 ) which contradicts this study findings where position 4 is the most common position. Khojastepour et al. (2015) ${ }^{13}$ in their cross sectional study on CBCT images, found that the MF was most commonly located in line with second premolar (position 4) which concurs with findings in this study.

Apinhasmit et al. in $2006^{25}$ evaluated the location of MF on dry mandibles in Thai population. They found that the majority of the MF $(69.57 \%)$ were located in the same vertical line with the long axis of the second premolars in both genders (position 4) followed by position 3 which is in agreement with the findings of this study. ${ }^{25}$

However they found no significant gender difference in location which contradicts the finding reported in this study where position 4 is more common in females and position 3 is more common in males.

In Turkish population, Gungor et $\mathrm{al}^{26}$ in 2006 examined 360 panoramic radiographs to evaluate the position of MF. They found that $71.5 \%$ MF was located in line with the first premolar $^{26}$, which contradict the finding of this study that reported position 4 (at line with second premolar) as the most common position of the studied sample. Alkhateeb et $\mathrm{al}^{27}$ in 1994 evaluated the position of the MF in Saudi population using panoramic radiographs and found that $83.7 \%$ of the sample had the MF located either at position 3 and 4 collectively. ${ }^{26}$ However he did not state the prevalence for each position, therefore, it is difficult to compare their result with this study.

In our study, the MF was found to be symmetrical in the majority of the samples, which is in agreement with the results reported by others. ${ }^{14,15,24,26,28}$ However, they found that position 4 was the most common position to be symmetrical, followed by position 3 whereas in this study, position 3 was the most symmetrical position followed by position 4.

Al Jasser and Nwoku in $19988^{14}$ concluded that the location of the MF is not gender related and this contradicts the finding of this study in which the location of MF in males was different than females.

Based on reports from different studies conducted on different populations, the location of the MF does show racial, ethnic and gender differences. ${ }^{11,13,15,28}$ Therefore, the location of the MF must be assessed based on the individual population, without consideration of its location in other different populations groups.

In 2D images MF may occasionally be misdiagnosed as a well-defined radiolucency related to the apex of mandibular premolars, or misinterpreted if there is enlarged marrow space mimicking the mental foramen. Such errors can be completely removed when utilizing $3 \mathrm{D}$ volume rendering.
Therefore, CBCT is recommended prior to any surgical procedure in the vicinity of MF region.

\section{CONCLUSION}

The location of MF is variable among different populations, and assuming a generic MF location can lead to unpleasant mental region paresthesia or anesthesia.. CBCT precisely localized the position of MF, and is strongly recommended before any surgical procedure involving the MF region.

\section{CONFLICT OF INTEREST}

The author of this manuscript has no conflict of interest to declare.

\section{REFERENCES}

1. Scarfe WC, Farman AG, Sukovic P. Clinical applications of conebeam computed tomography in dental practice. J Can Dent Assoc. 2006;72:75-80.

2. Scarfe WC, Farman AG. What is cone-beam CT and how does it work? Dent Clin North Am. 2008; 52:707-30

https://doi.org/10.1016/j.cden.2008.05.005

3. Miracle AC, Mukherji SK. Cone beam CT of the head and neck, part 1: physical principles. Am J Neuroradiol 2009; 30:1088-95. https://doi.org/10.3174/ajnr.A1653

4. Miracle AC, Mukherji SK. Cone beam CT of the head and neck, part 2: clinical applications. Am J Neuroradiol 2009b; 30:1285-92. https://doi.org/10.3174/ajnr.A1654

5. Fishel D, Buchner A, Hershkowith A, Kaffe I. Roentgenologic study of the mental foramen. Oral Surg Oral Med Oral Pathol 1976; 41: 682-86.

https://doi.org/10.1016/0030-4220(76)90325-X

6. Arzouman M J, Otis L, Kipnis V, Levine D. Observations of the anterior loop of the inferior alveolar canal. Int J Oral Maxillofac Implants 1993; 8: 295-300.

7. Bavitz JB, Harn SD, Hansen CA, Lang M. An anatomical study of mental neurovascular bundle-implant relationships. Int J Oral Maxillofac Implants 1993;8:563-67.

8. Phillips J L, Weller RN, Kulild JC. The mental foramen: Size and position on panoramic radiographs. J Endod 1992;18:383-86. https://doi.org/10.1016/S0099-2399(06)81224-0

9. Yosue T, Brooks SL. The appearance of mental foramina on panoramic radiographs. I. Evaluation of patients. Oral Surg Oral Med Oral Pathol 1989;68:360-64.

https://doi.org/10.1016/0030-4220(89)90224-7

10. Lindh C, Petersson A, Klinge B. Measurements of distances related 
to the mandibular canal in radiographs. Clin Oral Implants Res 1995; 6:96-103.

https://doi.org/10.1034/j.1600-0501.1995.060205.x

11. Naik MK, Sahu RK, Rath B, Rath S. Morphometric study of mental and accessory mental foramen in dry adult human mandibles in Southern Odisha population. J Dent Med Sci 2017;16:38-43.

12. von Arx T, Friedli M, Sendi P, Lozanoff S, Bornstein MM. Location and dimensions of the mental foramen: a radiographic analysis by using cone-beam computed tomography. J Endod 2013;39:1522-28. https://doi.org/10.1016/j.joen.2013.07.033

13. Khojastepour L, Mirbeigi S, Mirhadi S, Safaee A. Location of Mental Foramen in a Selected Iranian Population: A CBCT Assessment. Iran Endod J 2015;10:117-21.

14. Al Jasser N M, Nwoku AL. Radiographic study of the mental foramen in a selected Saudi population. Dentomaxillofac Radiol 1998; 27:341-43. https://doi.org/10.1038/sj.dmfr.4600388

15. Al-Mahalawy H, Al-Aithan H, Al-Kari B, Al-Jandan B, Shujaat $\mathrm{S}$. Determination of the position of mental foramen and frequency of anterior loop in Saudi population. A retrospective CBCT study. Saudi Dent J 2017;29:29-35.

https://doi.org/10.1016/j.sdentj.2017.01.001

16. Santini A, Land M. A comparison of the position of the mental foramen in Chinese and British mandibles. Acta Anat 1990;137: 208-12.

https://doi.org/10.1159/000146822

17. Mwaniki D L, Hassanali J.The position of mandibular and mental foramina in Kenyan African mandibles. East Afr Med J 1992;69: 210-13.

18. Shankland WE 2nd. The position of the mental foramen in Asian Indians. J Oral Implantol 1994;20:118-23.

19. Moiseiwitsch J R. Position of the mental foramen in a North American, white population. Oral Surg Oral Med Oral Pathol Oral
Radiol Endod 1998;85:457-60.

https://doi.org/10.1016/S1079-2104(98)90074-9

20. Aktekin M, Celik H H, Aldur M M, Aksit MD. Studies on the location of the mental foramen in Turkish mandibles. Morphologie 2003;87:17-19.

21. Pyun JH, Lim YJ, Kim MJ, Ahn SJ, Kim J. Position of the mental foramen on panoramic radiographs and its relation to the horizontal course of the mandibular canal: a computed tomographic analysis. Clin Oral Implants Res;2013;24:890-95. https://doi.org/10.1111/j.1600-0501.2011.02400.x

22. Madrigal C, Ortega R, Meniz C, Lopez-Quiles J. Study of available bone for interforaminal implant treatment using cone-beam computed tomography. Med Oral Patol Oral Cir Bucal 2008; 13: E307-312.

23. Devlin H, Yuan J. Object position and image magnification in dental panoramic radiography: a theoretical analysis. Dentomaxillofac Radiol 2013;42:29951683.

https://doi.org/10.1259/dmfr/29951683

24. Ngeow W C, Yuzawati Y. The location of the mental foramen in a selected Malay population. J Oral Sci. 2003; 45: 171-75.

https://doi.org/10.2334/josnusd.45.171

25. Apinhasmit W, Methathrathip D, Chompoopong S, Sangvichien $S$ Mental foramen in Thais: an anatomical variation related to gender and side. Surg Radiol Anat. 2006; 28: 529-533.

https://doi.org/10.1007/s00276-006-0119-7

26. Gungor K, Ozturk M, Semiz M, Brooks SL. A radiographic study of location of mental foramen in a selected Turkish population on panoramic radiograph. Coll Antropol 2006; 30:801-05.

27. Al-Khateeb TL, Odukoya O, el-Hadidy MA. Panoramic radiographic study of mental foramen locations in Saudi Arabians. Afr Dent J 1994; 8:16-19.

28. Jamdade AS, Yadav S, Bhayana R, Khare V, Pardhe N, Mathur, $\mathrm{N}$. Radiographic localization of mental foramen in a selected India population. Innovative J Med Health Sci 2013;3:249-53. 